\title{
Obstructive jaundice caused by hemobilia after liver biopsy
}

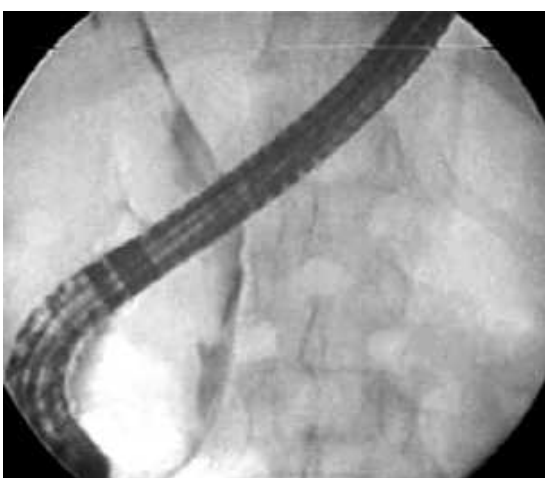

Fig. 1 Endoscopic retrograde cholangiopancreatography (ERCP) demonstrated mild dilation of the common bile duct with a long longitudinal mobile filling defect suggesting the presence of a blood clot.

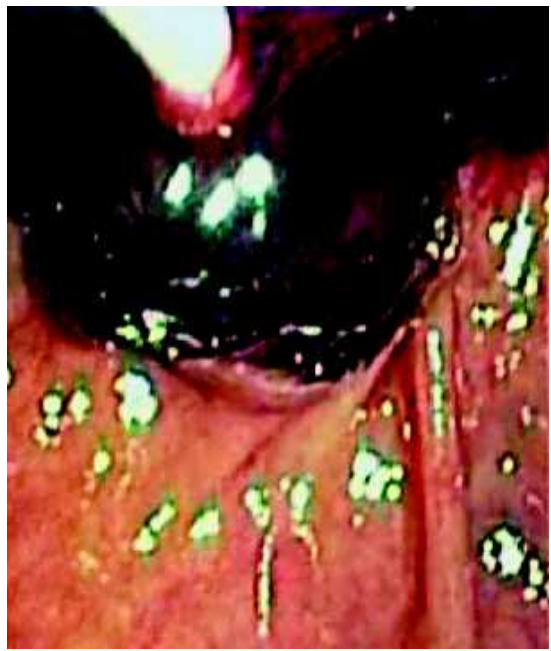

Fig. 2 Endoscopic view of a clot being retrieved using a balloon after the sphincterotomy.

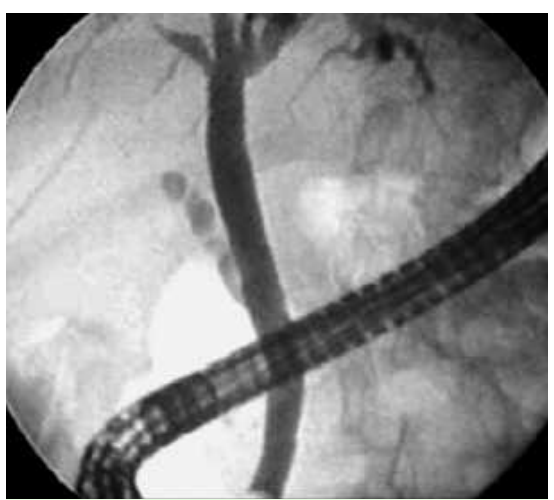

Fig. 3 Occlusion cholangiogram revealing clearance of the bile duct.

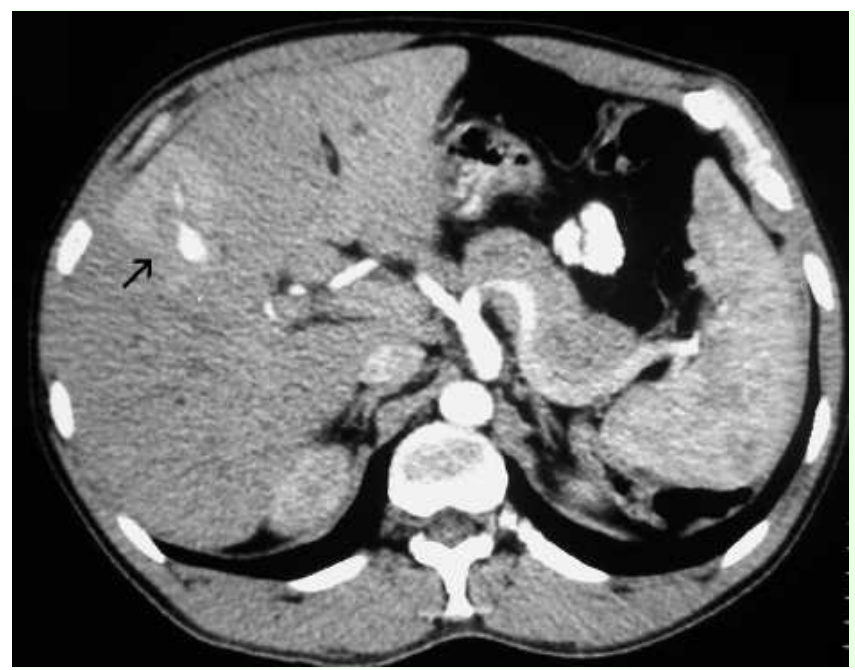

Fig. 4 Abdominal CT scan showing a slightly dilated biliary tree with the suggestion of an arteriobiliary fistula (arrows).
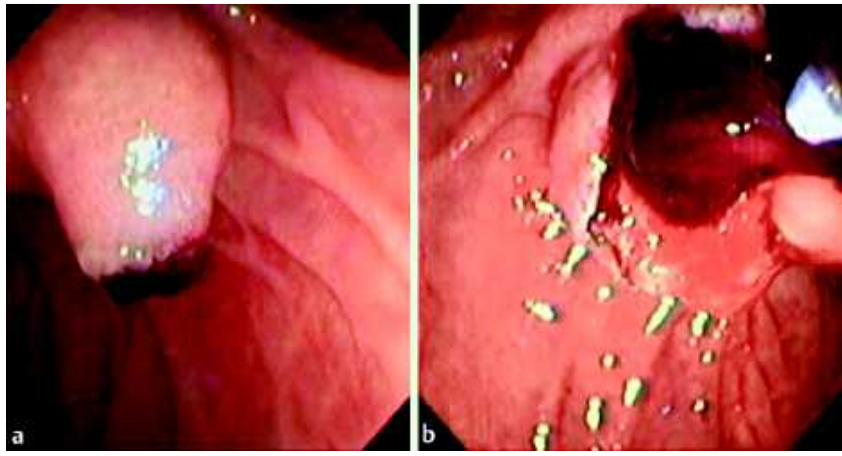

Fig. 5 a ERCP showed an enlarged major papilla obstructed by a blood clot. b Large blood clots were drained after sphincterotomy.

Hemobilia due to arteriobiliary duct fistula is a rare complication of percutaneous liver biopsy [1-3] typically presenting with jaundice, pain, and bleeding [4]. The role of endoscopic retrograde cholangiopancreatography (ERCP) is well established $[1,5]$. We report two cases successfully treated with sphincterotomy and clot removal.

Case 1. A 45-year-old woman with a clinical diagnosis of cirrhosis underwent liver biopsy. She had a past history of cholecystectomy. There was no evidence of any complication shortly after the biopsy. After 5 days, although otherwise asymptomatic, she developed jaundice (total bilirubin $5 \mathrm{mg} / \mathrm{dL}$ ). Abdominal ultrasound showed a slightly dilated common bile duct (CBD). She was referred for ERCP, which demonstrated mild dilation of the CBD with a long longitudinal mobile filling defect ( $\odot$ Fig. 1) corresponding to a large blood clot filling the whole duct.
After sphincterotomy the clot was retrieved using a balloon ( $\bullet$ Fig. 2).

Cholangiography following intraductal clot removal demonstrated clearance of the filling defect ( $\bullet$ Fig. 3, Video 1 ).

The patient recovered uneventfully with no further bleeding.

Case 2. A 37-year-old man with a past history of blood transfusion and elevated liver enzymes underwent liver biopsy. Viral serology findings were negative and autoimmune disease had also been dis-

\section{Video 1}

Endoscopic retrograde cholangiopancreatography (ERCP) demonstrated mild dilation of the common bile duct with a long longitudinal mobile filling defect suggesting the presence of a blood clot. Sphincterotomy was performed and a large clot was retrieved using a balloon. Final occlusion cholangiogram revealing clearance of the bile duct. 
closed. There was no evidence of early complications after the procedure. Four days after the biopsy the patient presented with jaundice, fever, and severe abdominal pain. Liver enzymes and bilirubin were slightly raised (total bilirubin $9.3 \mathrm{mg} / \mathrm{dL}$ ). Abdominal CT scan revealed a mildly dilated biliary tree with the suggestion of an arteriobiliary fistula (๑ Fig. 4, arrows).

ERCP disclosed an enlarged major papilla obstructed by a blood clot ( $\odot$ Fig. 5 a).

A large filling defect was present in the dilated CBD suggestive of biliary obstruction resulting from hemobilia. When sphincterotomy was performed, large blood clots were drained ( $\odot$ Fig. 5 b, Video 2 ).

The final occlusion cholangiogram demonstrated no further filling defects and absence of a biliary fistula.

Endoscopy_UCTN_Code_CCL_1AZ_2AO
F. Prata Martins, D. R. Bonilha, L. P. Correia, A. Paulo Ferrari

Endoscopy Unit, Universidade Federal de

São Paulo (UNIFESP), São Paulo, Brazil

\section{References}

1 Sciumè C, Geraci G, Pisello F et al. An uncommon complication of liver biopsy: obstructive jaundice from blood clots. Ann Ital Chir 2005; 76: 579-581

2 Edden Y, St Hilaire H, Benkov Ket al. Percutaneous liver biopsy complicated by hemobilia-associated acute cholecystitis. World J Gastroenterol 2006; 12: 4435-4436

3 Moon W, Sohn JH, Jang MH et al. A case of acute cholecystitis secondary to hemobilia after percutaneous liver biopsy [in Korean] Korean J Gastroenterol 2006; 47: 72 - 76

4 Kroser J, Rothstein RD, Kochman ML. Endoscopic management of obstructive jaundice caused by hemobilia. Gastrointest Endosc 1996; 44: 618-619

5 Worobetz LJ, Passi RB, Sullivan SN. Hemobilia after percutaneous liver biopsy: role of endoscopic retrograde cholangiopancreatography and sphincterotomy. Am J Gastroenterol 1983; 78: 182 - 184
Bibliography

DOI $10.1055 / \mathrm{s}-2008-1077651$

Endoscopy 2008; 40: E265 - E266

(c) Georg Thieme Verlag KG Stuttgart · New York . ISSN 0013-726X

\section{Corresponding author}

\section{F. Prata Martins, MD, PhD}

Endoscopy Unit, Universidade Federal de São Paulo (UNIFESP)

AL Ministro Rocha Azevedo, 976 apt 71

CEP 01410-002

São Paulo - SP

Brazil

Fax: +55-11-55764050

fernandaprata@terra.com.br

\section{Video 2}

Duodenoscopy showed an enlarged major papilla obstructed by a blood clot. After sphincterotomy was performed large blood clots were drained and a balloon was used to clear the biliary tree. 